\title{
Optimal Design and Operation of a Low Carbon Community based Multi-energy Systems Considering EV Integration
}

\author{
Jun Cao, Member, IEEE, Constance Crozier, Student Member, IEEE, Malcolm McCulloch, Senior Member, IEEE, \\ and Zhong Fan, Senior Member, IEEE,
}

\begin{abstract}
Hybridization of electricity, heat power and transportation energy combines the advantages of multi-energy sources. This paper proposes the combined use of fuel cell, combined heat and power units (CHP), hot water tank storage, gas boiler and photovoltaic (PV) generators to meet the electrical, thermal and transportation electrification energy demands in an eco-friendly multi-energy microgrid. An optimal energy balance methodology is proposed in this paper for sizing the capacity of fuel cell, CHP, gas boiler and PV. The method is to minimise the total annual cost and emissions of the whole system, based on hourly electrical and thermal load profile. The methodology can be used as a planning tool for multi-energy systems.
\end{abstract}

Keywords-Optimal sizing, Energy balance, Fuel cell, Thermal Storage, Transportation Electrification

\section{INTRODUCTION}

Low carbon multi-energy systems have gained increasing attention recently, due to their efficiency, flexibility and environmental impact. The generation of a multi-energy system can mix a wide range of power sources including renewable energy, CHP, fuel cell and storage. Hybridization of different technologies that complement each other can guarantee both reliability and economy.

One of the challenges for planning and operation of this multi-energy system is that the supply of heat and electricity energy is a highly coupled co-optimisation problem. Fig. 1 shows the configuration of a multi-energy microgrid system. The fuel cell and electric heater make the heat and electricity energy highly coupled. Extensive work has been done on optimal operation of multi-energy systems. An integrated strategy for supplying heating, cooling and power in small scale distributed networks which incorporates renewables is proposed in [1]. An integrated power and heating energy system, including a detailed CHP model is adopted in [2], [3] to accommodate more wind powers. Reference [4] is focused on utilizing customers' flexible energy demand, including both heat demand and electricity demand, to provide balancing resources and relieve the difficulties of integrating variable wind power with the CHP. In [5], a scenario-based approach is proposed for the stochastic operation of integrated electric power, natural gas and heat delivery systems. However, the scope is limited to a subset of resources and does not provide

This work is partly supported by the SEND project (grant 32R16P00706) funded by ERDF and BEIS

J. Cao and Z. Fang are with Keele University, UK, ST5 5BG (Corresponding author: Jun Cao, email: jcao01@qub.ac.uk).

C. Crozier and M. McCulloch are with Energy and Power Group, Department of Engineering Science, University of Oxford.

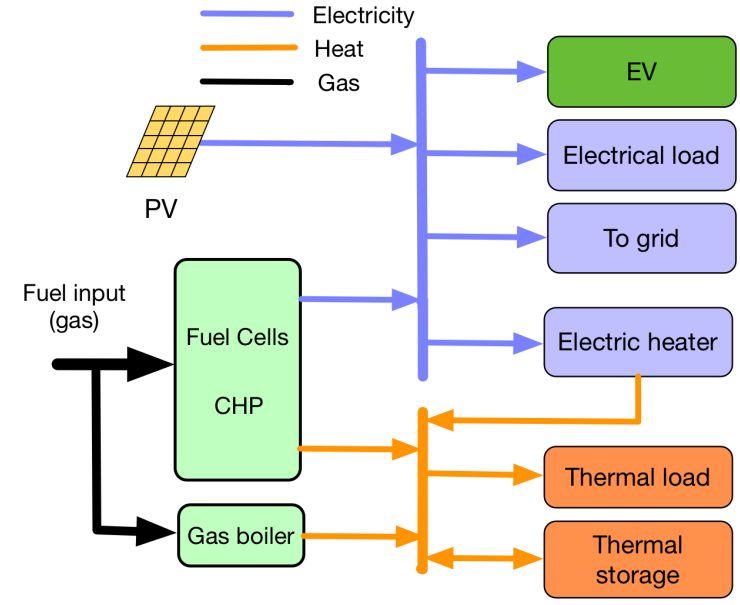

Fig. 1. Configuration of Multi-energy Microgrid.

a framework of designing a microgrid with multi-energy carrier systems.

A reasonable design considering the optimal operation of the system is an important premise for stable, economical and efficient operation of a multi-energy system. In [6], the authors propose a tri-level collaborative optimizing strategy for the integrated design of hybrid cooling, heating and power system. A power source sizing strategy with integrated consideration of wind turbine, PV, CHP and Electric Vehicles (EVs) is presented in [7] to calculate the optimal configuration of energy storage. Reference [8] developed a mixed integer linear program for the optimal design of distributed energy systems, but Electric Vehicles were neglected in the analysis.

Recently, several studies focused on the design and operation of microgrid with Electric Vehicles [7]. EVs in the UK are expected to increase dramatically in the coming years. Reference [9] predicts that by the year of 2040, more than half of the vehicles running on the road will be electric. The propagation of EVs could help the government achieve its reduced carbon and emissions targets, particularly if most of the electricity used to power EVs is from renewable generations. However, the widespread adoption of EVs will bring some challenges to the grid and one of the biggest is that vehicle charging will significantly change the electricity demand profile. Thus, it is necessary to consider the EV integration in the sizing and energy management study. However, from the analyzed literature on multi-energy systems, there is relatively little consideration of $\mathrm{EV}$ integration.

In this paper, we introduce the use of fuel cells, CHP, gas 
boilers, hot water tank storage and PV to meet the electrical and thermal demand considering the transport electrification in an eco-friendly multi-energy microgrid. The main contributions of the paper are:

1) The paper proposes a mixed integer linear optimization model for the design and operation of a low carbon multienergy system by using mixed low carbon technologies. The simulation includes: a grid scale fuel cell model based on MCFCs (Molten Carbonate Fuel Cells), a detailed dynamic thermal model for a house, and a two mass composite model of a thermal storage which considers the stratification of the hot water tank.

2) A model of transportation electrification considering both uncontrolled and smart charging of EVs is proposed based on the UK national travel survey data. The smart charging model for EV proposed in the paper employs a novel and simple demand-profile based method, which requires minimal communication.

The rest of the paper is organized as follows. The models of the fuel cell, a house and thermal storage are described in Section II. The model of transportation electrification is presented in Section III. In Section IV, an optimal sizing and operation modelling framework is proposed. Simulation results are provided in Section V, with conclusions presented in Section VI.

\section{SySTEM MODEL}

\section{A. Fuel cell model}

The fuel cell power plant can provide high quality baseload electric and heat power using natural gas or anaerobic digester gas as fuel. Compared with traditional combustion CHP units, some key features and advantages of the fuel cell power plant include: 1) No active cooling requirement in case of missing thermal off take; 2) Higher electrical efficiency (up to $60 \%$ NET) to any competing CHP system; 3) Low noise emissions due to no vibration; 4) Reduced maintenance; 5) Constant emission and efficiency level, even at reduced output; 6) Toxic exhaust far below any emission threshold. The heat and power output of the fuel cell are coupled and restricted within certain boundaries. The operation constraints of fuel cell are modelled as follows:

1) Power ramp limits of fuel cell: The power output variability of the fuel cell is affected by its ability to maintain stable temperatures during transitions, as the stack and balance of plant components can be damaged if the operating temperature is changed too quickly. During normal operation, the fuel cell power output $P_{f c}(t)$ with ramp up or down at rates of $10 \%$ per hour stages is defined as:

$$
-0.1 P_{f c}^{\max } \leq P_{f c}(t)-P_{f c}(t-1) \leq 0.1 P_{f c}^{\max },
$$

where $P_{f c}^{\max }=n P_{f c}^{\mathrm{cap}}$ is the power output limit of fuel cell with $n$ the number of fuel cells and $P_{f c}^{\mathrm{cap}}$ the capacity of individual fuel cell.

2) Power capacity limit: The fuel cell system can produce up to a capacity limit at full load and can be throttled back to $50 \%$ of the capacity, which is modelled as:

$$
0.5 P_{f c}^{\max } \leq P_{f c}(t) \leq P_{f c}^{\max } .
$$

3) Relationship between electric and heat power: Regarding the relationship between power and heat, firstly, please note that as the stack ages, electrical output decreases and heat output increases. The thermal to electric output ratios of the fuel cell stack and fuel cell sub-system are shown in the following equation. The heat rejection from the stack increases with decreasing electric efficiency.

$$
H_{f c}(t)=r_{\mathrm{TE}}(t) P_{f c}(t),
$$

where $H_{f c}(t)$ is the waste heat available from the fuel cell system at time $t$ and $r_{\mathrm{TE}}(t)$ is the thermal to electric output ratio of the fuel cell system; this ratio will gradually increase by $10 \%$ by the end of the stack ages (normally 5 years).

\section{B. CHP model}

The relationship between the heat and electric power generation of CHP plant is stated as:

$$
Q_{C H P}(t)=P_{C H P}(t) \cdot \frac{1-\eta_{C H P}(t)-\eta_{1}}{\eta_{C H P}(t)}
$$

where $P_{C H P}(t), Q_{C H P}(t)$ are the electric and heat power generated by CHP at time $t$, respectively; $\eta_{C H P}, \eta_{1}$ are the efficiency and heat loss factor of CHP, respectively.

The natural gas consumption related to the electric output of CHP can be obtained as follow:

$$
G_{C H P}(t)=\frac{P_{C H P}(t)}{L_{C H P} \cdot \eta_{C H P}}
$$

where $L_{C H P}$ is the low heating value of natural gas $\left[k W h / m^{3}\right]$.

\section{Dynamic thermal model of a house}

A thermal model of a house created in Simulink is adopted to calculate the thermal consumption. The model includes the outdoor environment, the thermal characteristics of the house, and the house heating system. The room temperature of a house is determined by the heat flow from the heater and the heat losses to the environment. Heat losses, denoted by $Q_{\text {losses }}$, and room temperature, denoted by $T_{\text {room }}$ are expressed by

$$
\begin{array}{r}
\frac{d Q_{\text {losses }}}{d t}=\frac{T_{\text {room }}-T_{\text {out }}}{R_{\text {eq }}}, \\
\frac{d T_{\text {room }}}{d t}=\frac{1}{c M_{\text {air }}}\left(\frac{d Q_{\text {heater }}}{d t}-\frac{d Q_{\text {losses }}}{d t}\right),
\end{array}
$$

where $M_{\text {air }}$ is the mass of air inside the house; $R_{\text {eq }}$ is the equivalent thermal resistance of the house; $c$ is the heat capacity of air at constant pressure; $T_{\text {out }}$ is the outdoor temperature; and $P_{\text {heat }}(t)=\frac{d Q_{\text {heater }}}{d t}$ is the heater power.

The state-space model in continuous time (7) can be transformed into the equivalent first-order state-space discrete time model by using Euler discretisation with a sampling time of $T_{s} \quad[10],[11]$ as

$$
T_{\text {room }}(t+1)=a T_{\text {room }}(t)+b P_{\text {heat }}(t)+U
$$

where $a=1-\frac{1}{c M_{\text {air }} R_{\mathrm{eq}}}, b=\frac{1}{c M_{\text {air }}}$ and $U=\frac{T_{\text {out }}}{c R_{\mathrm{eq}} M_{\text {air }}}$ is an input variable. The discrete time thermal dynamic model (8) 
will be used in construction of the optimization problem. The constraints of the room temperature are represented as follows:

$$
T_{\text {room }}^{\min } \leq T_{\text {room }}(t) \leq T_{\text {room }}^{\max },
$$

where $T_{\text {room }}^{\min }$ and $T_{\text {room }}^{\max }$ are the lower and upper bounds of the room temperature limits considering the comfort range (e.g., $T_{\text {room }}^{\min }=21^{\circ} \mathrm{C}, T_{\text {room }}^{\max }=26^{\circ} \mathrm{C}$ ) respectively.

\section{Mathematical model of thermal storage}

A two mass composite model is adopted to simulate the dynamic thermal process of a thermal storage using a hot water tank. The water in the tank can be modelled as a stratified system layer of the hot water at the top and cool water at the bottom [12]. We assume that each storage layer has a constant temperature and a variable mass; the upper layer of the tank has a uniform temperature close to temperature setting (hot water) and the lower compartment of water has another uniform temperature close to inlet water temperature (cold water) [13]. This simple model is used to calculate the ratio of the hot water layer inside the tank, which has the same function as the state of charge (SoC) in a battery. The heat power balance of the upper layer and lower layer are obtained as

$$
\begin{aligned}
T_{a} C_{p} \frac{d m_{a}}{d t} & =\dot{Q}_{\mathrm{elec}}-\dot{m} C_{p} T_{a}-\dot{Q}_{\mathrm{loss}, \mathrm{a}}, \\
T_{b} C_{p} \frac{d m_{b}}{d t} & =\dot{m} C_{p} T_{b}-\dot{Q}_{\text {loss }, \mathrm{b}}, \\
\dot{Q}_{\text {loss,a }} & =2 \pi r h k\left(T_{a}-T_{\mathrm{amb}}\right), \\
\dot{Q}_{\text {loss } \mathrm{b}} & =2 \pi r k(H-h)\left(T_{b}-T_{\mathrm{amb}}\right),
\end{aligned}
$$

where $\dot{Q}_{\text {loss,a }}$ is the loss of upper layer; $\dot{Q}_{\text {loss,b }}$ is the loss of lower layer; $\dot{Q}_{\text {elec }}$ is the heat power of the resistor in the water heater; $T_{\mathrm{amb}}$ is the outside temperature of the tank; $r$ is the radius of the tank; $h, H$ are the height of hot water layer and the tank, respectively; $k$ is the thermal conductivity coefficient; $C_{p}$ is the specific heat capacity of water; $T_{a}\left(T_{b}\right)$ is the water temperature of the upper (lower) layer; $m_{a}\left(m_{b}\right)$ is the water mass of the upper (lower) layer; and $\dot{m}$ is the water mass flow rate.

Assume the mass flow rate entering the tank is equal to the mass flow rate exiting the tank and the temperature $T_{\mathrm{amb}}=$ $T_{b}$. Thus, the mass conservation laws can be represented as $\frac{d m_{a}}{d t}+\frac{d m_{b}}{d t}=0$ and (10), (11) may be rewritten as

$$
\left(T_{a}-T_{b}\right) C_{p} \frac{d m_{a}}{d t}=\dot{Q}_{\mathrm{elec}}-\dot{Q}_{\mathrm{load}}-\left(T_{a}-T_{b}\right) 2 \pi r h k
$$

where $\dot{Q}_{\text {load }}=\dot{m} C_{p}\left(T_{a}-T_{b}\right)$. We denote by $\eta=h / H$ the ratio of hot water layer to the tank height; then by using (14) we have

$$
\frac{d \eta}{d t}=c\left(\dot{Q}_{\mathrm{elec}}-\dot{Q}_{\mathrm{load}}\right)-d \eta,
$$

where $c=1 /\left[H\left(T_{a}-T_{b}\right) C_{p} \rho A\right]$ and $d=2 \pi r k / C_{p} \rho A$. The discretised state space model of (15) can be obtained as

$$
\eta(t+1)=(1-d) \eta(t)+c\left(\dot{Q}_{\mathrm{elec}}-\dot{Q}_{\mathrm{load}}\right) .
$$

\section{MODEL OF TRANSPORTATION ELECTRIFICATION}

The electrification of personal transport stands to drastically increase household demand for electricity. There are several steps involved in predicting the power demanded by a partially electrified fleet of personal vehicles. First, the usage of the residential EVs must be predicted. Second, the resulting electricity consumption of the EVs needs to be estimated. Finally, the charging behaviour of the vehicle owners must be modelled, to convert the power demanded of the EV battery to the power demanded of the grid.

\section{A. Vehicle usage}

As EVs have only recently become available, only very limited usage data is available. As their prevalence increases the behaviour of EV drivers is likely to converge with that of conventional vehicle drivers, which has been studied for many years. By sampling from a large travel survey (e.g. [14]) relevant usage profiles can be extracted; profiles which were observed in similar areas and at similar times to those under investigation. The usage profiles constitute a journey $\log$, where the times, distances, and purposes of all journeys undertaken by the vehicle are recorded.

Once a subset of profiles have been gathered they must be scaled to represent the required number of vehicles. The required number of vehicles is determined by scaling the total number of vehicles by the percentage assumed to be electric. If the number of profiles exceeds the required number then a random subset are chosen. If not, then the power demanded by each of the vehicles is scaled by the ratio of the number of required vehicles to number of profiles.

In this paper a small town in the South East of the UK was chosen. Profiles from this region and of the relevant ruralurban classification were isolated. Separate simulations were done for each weekday and month and the predictions were combined to create a year round usage profile.

\section{B. Electricity Consumption}

Given the distances travelled by a vehicle, we need to estimate the electricity which would've been used completing it. In reality this will depend on many factors, including driver style, vehicle make and ambient conditions - information which we do not have. Here we use the model defined in [15], which uses vehicle and seasonal parameters to map the distance covered into an energy expenditure. This non-linear model uses standard drive cycles to capture different styles of driving - such as urban and motorway.

The energy used by the vehicle is not exactly equal to that required from the network; losses in charging need to be accounted for. The energy demanded from a network is assumed to be given by:

$$
E^{\text {demand }}=\frac{1}{\eta_{c}} E^{r e q}
$$

where $E^{r e q}$ is the amount of energy required to replenish the battery and $\eta_{c}$ is the charging efficiency. An efficiency of $90 \%$ was used for the simulation, as this level has been observed in situations similar to at home charging [16]. 


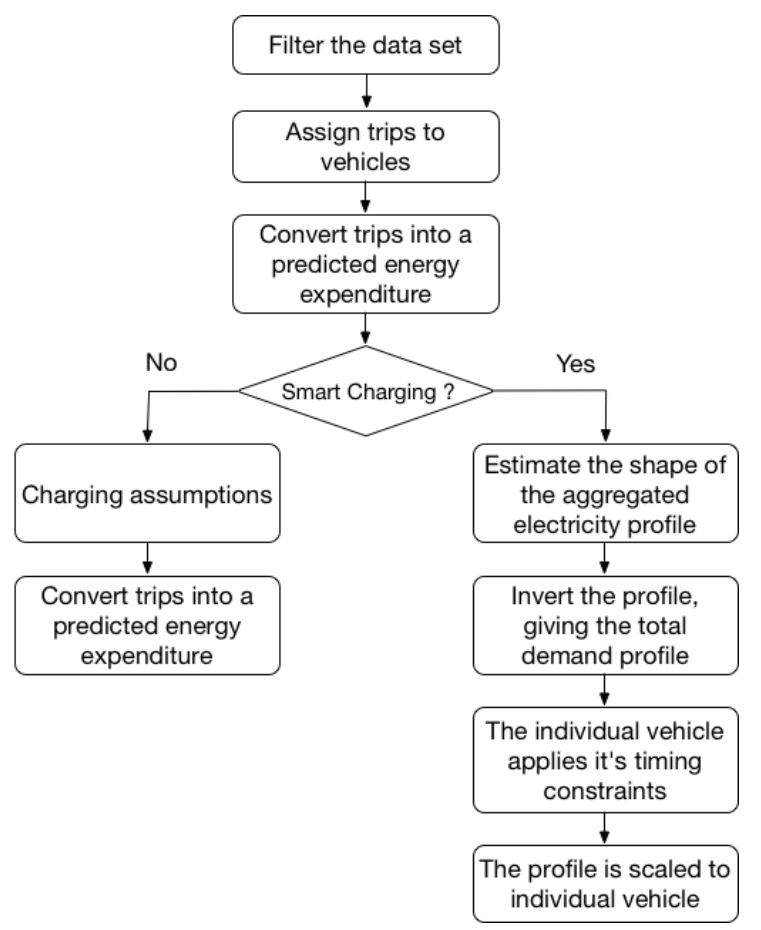

Fig. 2. Flowchart of the charging assumptions.

\section{Charging assumptions}

The way in which vehicles are charged will significantly affect the household power demand profile. Only uni-directional charging is allowed, meaning the possibility of the EV to provide vehicle-to-grid services has been ignored. Two types of charging mode are consider in the paper: 1) Uncontrolled Charging; 2) Smart Charging, which are shown in Fig. 2.

1) Uncontrolled Charging: we assume that each vehicle charges every day in which it is used, and charges until full. Charging is assumed to begin immediately after the completion of a vehicles' final journey and is carried out at a slow-charging rate of $3.5 \mathrm{~kW}$, which is a typical power rating for at-home chargers.

These assumptions result in a coincidence of the vehicular charging and existing household demand peaks, however this is far from the worst-case scenario. Assuming that each vehicle charges every day means most charges are short, which reduces the likelihood of a large number of EVs charging simultaneously.

2) Smart Charging: A simple smart charging control method, which requires minimal communication is adopted in the analysis. An illustration of the control scheme is shown in Fig. 3 and the procedure of the method is described below:

(I) estimate the shape of the aggregated electricity profile which you wish to valley-fill;

(II) invert the profile, giving the total demand profile which the aggregated vehicles should follow in order to completely flatten the overall demand;

(III) The individual vehicle applies its timing constraints (red dotted lines) and calculates the energy under the remaining charging profile;

(IV) The profile is scaled so that the vehicle will receive exactly the amount of energy it requires so that it will be fully charged just before it is next needed.
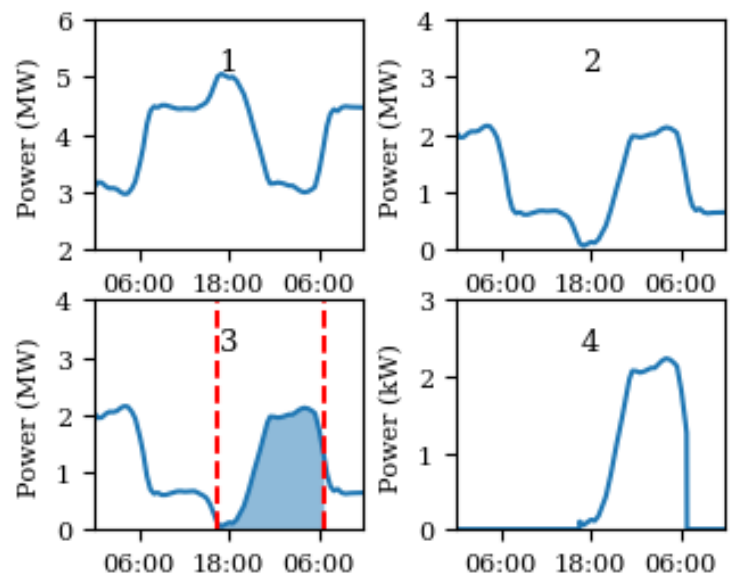

Fig. 3. Illustration of smart charging.

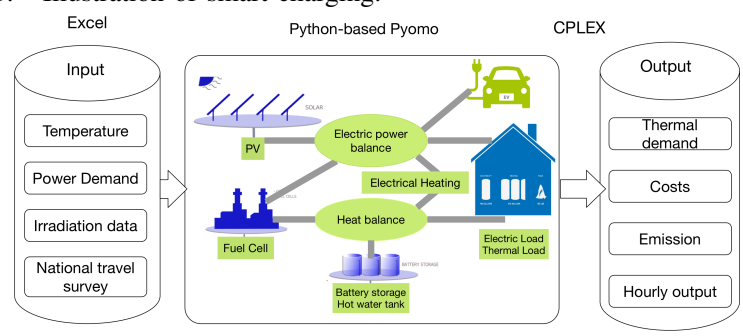

Fig. 4. Framework of the proposed algorithm.

\section{Optimal Sizing and Operation Modelling FORMULATION}

In this section, we propose an integrated power and heat optimisation model, which includes general model structure, objective function and constrains.

\section{A. General modelling framework}

The general framework is shown in Fig. 4. The inputs include hourly power demand, hourly ambient temperature and irradiation data. The outputs include costs and emissions. The objective function of the problem is to minimise the costs of the system, including equipment cost and operational cost of fuel cell, CHP, gas boiler and PV. The constraints that are taken into account represent: power ramp limits of fuel cells; relationship between power and heat (e.g. as the stack ages, electrical output decreases and heat output increases); energy balance; heat balance; fuel cells operation constraint; and ratings of fuel cells. The resulting optimisation problem is a mixed integer linear program which describes the joint operation of power and heat system on an hourly basis, considering the thermal storage.

\section{B. Objective Function}

The objective function includes total equipment costs of fuel cell, thermal storage and fuel costs of fuel cells.

1) Annual investment cost of the whole system: The annual investment costs of the whole system are defined by the following equation:

$$
C_{i n v}=a\left(N_{f c} C_{f c}+P_{p v, c} C_{p v}+N_{c h p} C_{c h p}+N_{b o i l} C_{b o i l}\right)
$$


where $C_{f c}, C_{p v}, C_{c h p}, C_{b o i l}$ are the investment costs of the fuel cell, PV, CHP unit and gas boiler, respectively. An annual factor $a$ is adopted to calculate the annual investment cost of each equipment, which is defined as:

$$
a=\frac{(1+i)^{n} \cdot i}{(1+i)^{n}-1}
$$

where $i$ is the interest rate and $n$ is the project lifetime.

2) The operation and maintenance cost: The annual O\&M cost is defined as

$$
C_{o m}=C_{f c, o m}+C_{c h p, o m}+C_{b o i l, o m}
$$

where $C_{f c, o m}, C_{c h p, o m}, C_{b o i l, o m}$ are the operation and maintenance cost of fuel cell, CHP and gas boiler, respectively.

3) Cost of power exchanging (in grid-connected mode): The annual cost of purchasing power from the grid $C_{g i m}$ and the revenue of selling power to the grid $C_{g e x}$ are defined as

$$
\begin{aligned}
C_{\text {gim }} & =\sum_{t=1}^{N T} P_{\text {grid }_{i m}}(t) \cdot p_{i m}(t) \\
C_{\text {gex }} & =\sum_{t=1}^{N T} P_{\text {grid }_{e x}}(t) \cdot p_{e x}(t)
\end{aligned}
$$

where $p_{i m}(t), p_{e x}(t)$ are the price of selling power to the grid and purchasing power from the grid, respectively.

4) Cost of Carbon Emission: The annual cost of the carbon emission depends on the generation output of fuel cell, CHP, gas boiler and imported electricity from grid.

$$
\begin{aligned}
C_{\text {carbon }}= & p \cdot\left(g_{f c} \sum_{t=1}^{N T} P_{f c}(t)+g_{c h p} \sum_{t=1}^{N T} P_{c h p}(t)\right. \\
& \left.+g_{\text {boil }} \sum_{t=1}^{N T} Q_{b o i l}(t)+g_{\text {grid }} \sum_{t=1}^{N T} P_{\text {grid }_{i m}}(t)\right)
\end{aligned}
$$

where $p$ is the carbon emission price per tone. $g_{f c}, g_{c h p}, g_{b o i l}, g_{g r i d}$ are the coefficients of carbon emission per kWh for fuel cell, CHP, gas boiler and grid, respectively.

5) Total Costs of the System: The annual total costs for the whole system $C_{\text {total }}$ are defined as

$$
C_{\text {total }}=C_{i n v}+C_{o m}+C_{g i m}-C_{g e x}+C_{\text {carbon }} .
$$

\section{System constraints}

The system constraints include both equality and inequality constraints.

1) Electric power balance: The sum of the power output from the fuel cell and PV generators is equal to the electrical load at every time instance $t$

$$
\begin{aligned}
& P_{f c}(t)+P_{p v}(t)+P_{\text {grid }_{i m}}(t)+P_{L S E}(t)+P_{\text {sto }} u t(t)= \\
& P_{\text {load }}(t)+P_{\text {heat }}(t)+P_{\text {sto }_{i} n}(t)+P_{\text {grid }_{e x}}(t)
\end{aligned}
$$

where $P_{p v}(t)$ is the power output of PV at time $t ; P_{\text {load }}(t)$ is the electric load consumption at time $t ; P_{\text {grid }_{i m}}(t), P_{\text {grid }}(t)$ are the power import and fed into grid at time $t$, when it is working on grid-connected mode, respectively; and $P_{\text {heat }}(t)$ is the excess electricity to be used for heat up the water tank; $P_{L S E}(t)$ is the load curtailment at hour $t ; P_{\text {stoo }} u t(t)$ and $P_{s t o_{i} n}(t)$ are the output and input power of storage at time $t$, respectively.
2) Heat Power Balance: The heat power output of the fuel cell and electric heating equals the sum of heating load at every time instance $t$

$$
\begin{aligned}
\eta_{h} H_{f c}(t)+ & H_{\text {heat }}(t)+H_{\text {sto }_{o} u t}(t)= \\
& H_{s p}(t)+H_{h w}(t)+H_{\text {grid }}(t)+H_{\text {sto } n}(t)
\end{aligned}
$$

where $H_{\text {heat }}(t)=\eta_{h} P_{\text {heat }}(t)$ with $\eta_{h}$ the conversion efficiency from electric heating to thermal energy; $H_{f c}(t)$ is the heat power output of fuel cell at time $t ; H_{s p}(t), H_{h w}(t)$ are the heat power output load of space heating and hot water usage at time $t$, respectively; and $H_{\text {grid }}(t)$ is the slack variable; $H_{\text {stoo } u t}(t)$ and $H_{\text {sto } i n}(t)$ are the output and input power of thermal storage at time $t$, respectively..

3) PV ramp limit: The output of PV generators to the utility grid are restricted by regulations to maintain necessary power quality and reliability in the network, which may be modelled as

$$
-0.1 P_{p v}^{\max } \leq P_{p v}(t)-P_{p v}(t-1) \leq 0.1 P_{p v}^{\max } .
$$

4) Power Exchange Limit (in Grid-connected mode): The electric power exchanging between community and grid should satisfy:

$$
\begin{aligned}
& P_{\text {grid }}^{\min } \leq P_{\text {grid }_{i m}} \leq P_{\text {grid }}^{\max } \\
& P_{\text {grid }}^{\min } \leq P_{\text {grid }_{e x}} \leq P_{\text {grid }}^{\max }
\end{aligned}
$$

where $P_{g r i d}^{\min }, P_{g r i d}^{\max }$ are the minimum and maximum power exchanging limit, respectively.

\section{Reliability assessment}

1) Reliability indices: To assess the reliability of the system, four well-known reliability indices are adopted: expected load not supplied (ELNS), expected energy not supplied (EENS), loss of load expectation (LOLE) and loss of load probability (LOLP), which are defined as follows:

$$
\begin{gathered}
\mathrm{ELNS}=\sum_{s} \sum_{t} p_{s, t} \cdot L_{s, t}^{\prime} \\
\mathrm{EENS}=\sum_{s} \sum_{t} p_{s, t} \cdot E_{s, t}^{\prime} \\
\mathrm{LOLE}=\sum_{s} \sum_{t} p_{s, t} \cdot t_{s, t}^{\prime} \\
\mathrm{LOLP}=\frac{\sum_{s} \sum_{t} p_{s, t} \cdot t_{s, t}^{\prime}}{T} \times 100 \%
\end{gathered}
$$

where $L_{s, t}^{\prime}, E_{s, t}^{\prime}$ are the amount of load and energy not supplied due to the outage of component of $s$, respectively; $t_{s, t}^{\prime}$ is the time duration of the $s$ component outage; $T$ is the number of time blocks within a year; $p_{s, t}$ is the probability of unavailability of each component $s$ at hour $t$ can be obtained as:

$$
p_{s, t}=\mathrm{FOR}_{s} \times \prod_{s^{\prime} \neq s}\left(1-\mathrm{FOR}_{s^{\prime}}\right)
$$

The equipment forced outage rate (FOR) is statistically calculated forced outage probability of the unit for a long time period. In this paper, only FOR of PV is considered to lower the computational burden. 
We use equation (35) to define the time steps in which the loads of electricity are curtailed. $u_{e, t}$ is used to indicate the state of curtailment. It would be 1 if the load is curtailed at time $t$.

$$
M \cdot u_{e, t} \geq P_{L S E}(t) \geq 0
$$

2) Reserve constraints: To provide backup power when equipment outage is considered, the reserve capacity is utilized. The available reserve capacity is limited by the component maximum capacity and maximum ramp up, which are defined in (36) and (37), respectively.

$$
\begin{gathered}
R_{s, t} \leq P_{s, c a p}^{\max } \\
0 \leq R_{s, t} \leq \overline{R R_{s}^{\max }}
\end{gathered}
$$

where $R_{s, t}$ is the reserve capacity of component $s$ at hour $t$; $\overline{R R_{s}^{\text {mas }}}$ is the maximum ramp up of component $s ; P_{s, \text { cap }}^{\max }$ is the maximum capacity of component $s$.

The total reserve capacity of the system $R_{t o t, t}$ is expressed as:

$$
R_{t o t, t}=\sum_{s} R_{s, t}
$$

3) Reliability constraints: According to (30) and (34), the ELNS can be obtained as:

$$
\begin{aligned}
\mathrm{ELNS}=\sum_{s} \sum_{t} \mathrm{FOR}_{s} \times \prod_{s^{\prime} \neq s}\left(1-\mathrm{FOR}_{s^{\prime}}\right) \cdot u_{e, t} \\
\times\left(Q_{s, t}+R_{s, t}-R_{t o t, t}\right)
\end{aligned}
$$

ELNS is still nonlinear and we can use the technique mentioned in [20] to linearize it.

Based on (33) and (34), the LOLP can be expressed as:

$$
\mathrm{LOLP}=\frac{\sum_{s} \sum_{t} u_{s, t} \cdot \mathrm{FOR}_{s} \times \prod_{s^{\prime} \neq s}\left(1-\mathrm{FOR}_{s^{\prime}}\right)}{T} \times 100 \%
$$

Since the calculation results of ELNS is proportional to EENS, in this paper, only ELNS and LOLP indices are used to qualify the reliability of the muti-energy system. The obtained ELNS and LOLP at each year should be less than the targeted value of ELNS ${ }^{t a r}$, LOLP $^{\text {tar }}$, which are modeled in equation (41) and (42), respectively.

$$
\begin{aligned}
& \text { ELNS } \leq \text { ELNS }^{\text {tar }} \\
& \text { LOLP } \leq \text { LOLP }^{\text {tar }}
\end{aligned}
$$

\section{E. Overall framework}

The integrated optimisation problem can be modelled as follows:

$$
\begin{gathered}
\min _{P_{f c}(t), P_{p v}(t), H_{f c}(t)} C_{\text {total }} \\
P_{\text {chp }}(t), Q_{c h p}(t) \\
\text { subject to }
\end{gathered}
$$

$$
(1)-(3),(8)-(9),(16),(25)-(42) \text {. }
$$

\section{Case STUdies}

We propose a framework to determine the optimal size and operation strategy of a multi-energy microgrid. The optimization model is built based on the Python open source modelling language Pyomo [17] and is solved by Mixed Integer Linear Optimization Programming (MILP) provided by the CPLEX solver [18].

The method is tested on an Eco-town in the UK which is planning to build a 1700-households community. To capture the weekly and seasonal effects in the analysis, we use electrical load profiles based on the reports of the UK Energy Research Centre [19]. Hence the number of time blocks used to represent the load variation are 10 years $\times 4$ seasons $\times$ 3 weekday/saturady/sunday $\times 48$ hours $=5760$. The space heating and hot water usage are summed up for the thermal load profile. For the space heating load, we take a reasonably modern end-of-terrace house insulated to standards suggested in the Building Regulations for England and Wales, and the load is calculated by (8) based on the ambient temperature. The hot water demand data is obtained from an Energy and Saving Trust (EST) study. We use an NREL developed tool, so-called PVWatts, to determine the output of PV generation [21].

The targeted reliability indices ELNS ${ }^{\text {tar }}$ and LOLP ${ }^{\text {tar }}$ are chosen as 1 and $0.1 \%$, respectively. The forced outage rate (FOR) of PV is $2 \%$ in the analysis.

To demonstrate application of the proposed model, four scenarios (S1,S2,S3 and S4) including 19 test cases are presented in Table I. S1 is base case which uses CHP and gas boiler to meet the load. S2, S3 and S4 are the low, medium and high carbon scenarios, respectively.

\section{A. Sizing and Operation Results}

Fig. 5 shows the comparison results of optimal sizing and costs of different cases. The average costs of S4 is still less than S2 and S3, by about $66.07 \%$ and $27.85 \%$ respectively, although the carbon emission cost is included in the objective function. The mainly reason is that the equipment cost of fuel cell is expensive.

The costs on grid connected mode is always cheaper than off-grid mode, as the electricity from the grid is cheaper than from local generators. Comparing the costs of uncontrolled charging with smart charging when EV is integrated, smart

TABLE I. DESCRIPTION OF TEST SCENARIOS.

\begin{tabular}{ccccc}
\hline \hline S. & Case. & EV & Grid-Con. & Technologies \\
\hline S1 & 1 & No & Yes & CHP + Back-up Gas Boiler \\
\hline & 2 & No & No & Fuel Cell + PV + Gas Boiler \\
S2 & 3 & No & Yes & Fuel Cell + PV + Gas Boiler \\
& 4 & Yes & No & Fuel Cell + PV + Gas Boiler \\
& 5 & Yes & Yes & Fuel Cell + PV + Gas Boiler \\
& 6 & Smart* & No & Fuel Cell + PV + Gas Boiler \\
& 7 & Smart & Yes & Fuel Cell + PV + Gas Boiler \\
\hline & 8 & No & No & Fuel Cell + CHP + PV + Gas Boiler \\
& 9 & No & Yes & Fuel Cell + CHP + PV + Gas Boiler \\
S3 & 10 & Yes & No & Fuel Cell + CHP + PV + Gas Boiler \\
& 11 & Yes & Yes & Fuel Cell + CHP + PV + Gas Boiler \\
& 12 & Smart & No & Fuel Cell + CHP + PV + Gas Boiler \\
& 13 & Smart & Yes & Fuel Cell + CHP + PV + Gas Boiler \\
\hline & 14 & No & No & CHP + Gas Boiler \\
S4 & 15 & No & Yes & CHP + Gas Boiler \\
& 16 & Yes & No & CHP + Gas Boiler \\
& 17 & Yes & Yes & CHP + Gas Boiler \\
& 18 & Smart & No & CHP + Gas Boiler \\
& 19 & Smart & Yes & CHP + Gas Boiler \\
\hline \hline & & & & *Smart charing mode
\end{tabular}




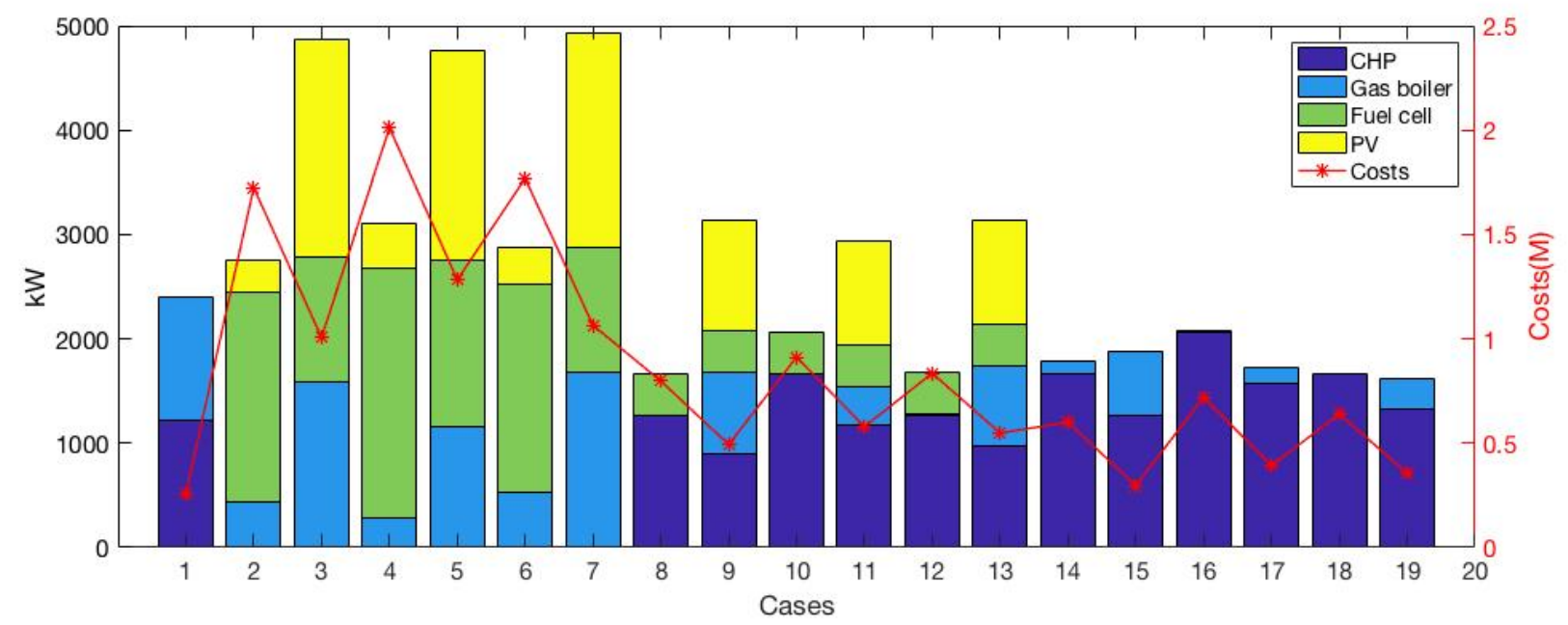

Fig. 5. Optimal sizing results and system costs of different cases.

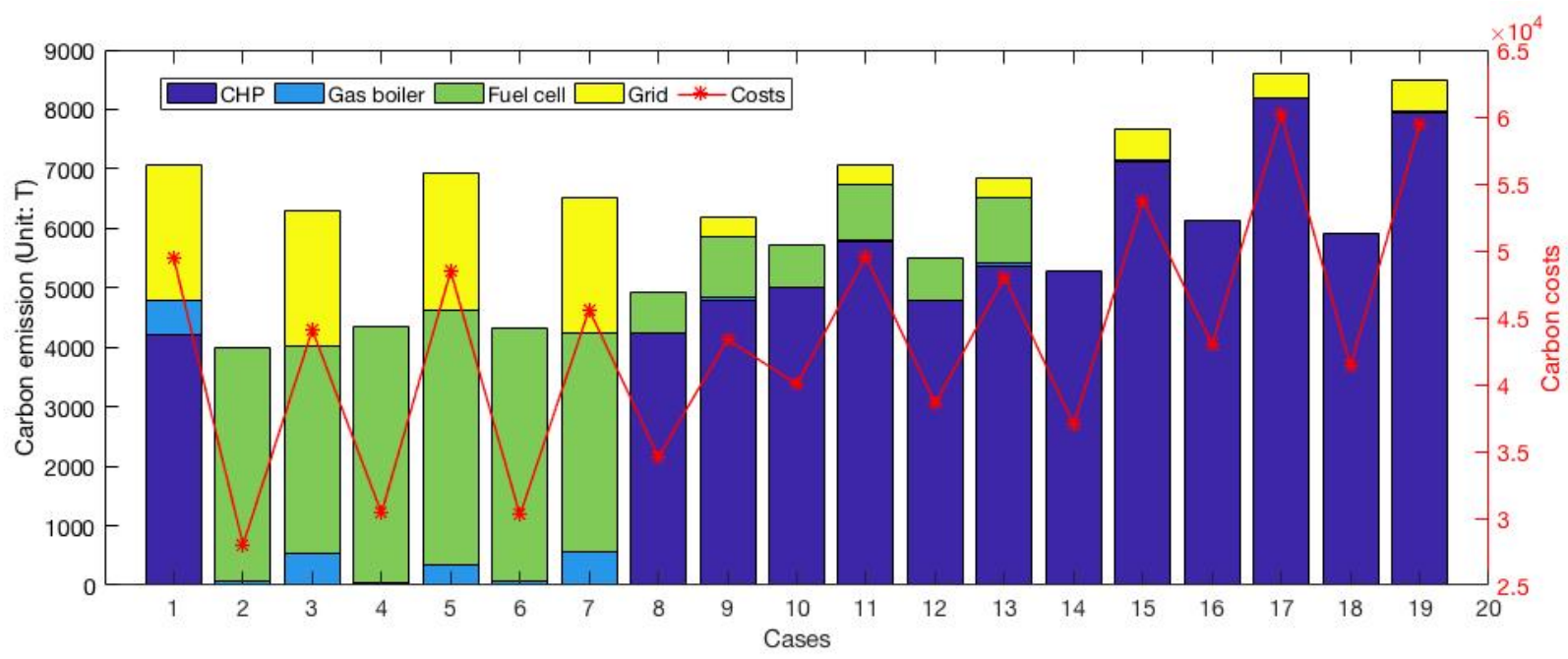

Fig. 6. Carbon emission results and costs of different cases.

charging mode is always less than the the uncontrolled charging mode. For example, the cost of case 18 is reduced by $12.45 \%$, compared with case 16 , as the smart charging smooths the electric load profile, as shown in Fig. 5.

The hourly power output for each type of the power generation for case 3 is shown in Fig. 7. During the winter season, the peak thermal load is almost twice as much as the peak load of electric power. Thus, almost all the electric power is supplied by the fuel cell during the winter to secure the required source of heat demand. During the summer periods, the peak thermal load is mainly the hot water usage which is almost the same as the peak electric power load. Part of the electric power is generated by the PV generators and the gas boiler power undertakes the peak heat demand.

In Fig. 8, the hourly energy balance for January and July for case 5 is depicted. When EVs are integrated with uncontrolled charging, the peak electric load increases by $25 \%$, compared with case 3 without EVs. The integration of EVs increases the cost of the system by $27.47 \%$. Fig. 10 shows the hourly energy balance for January and July for case 7. When EVs are integrated with smart charging, the maximum level of electric load doesn't change too much and the minimum level of the load increases by $50 \%$, compared to without EVs. The integration of smart charging EVs saves the cost of the system by $20.42 \%$, compared with case 5 .

\section{B. Carbon Emission Results}

The results of carbon emissions and the relative carbon costs for different cases are summarized in Fig. 6. Case 2 has the lowest carbon emissions, as it adopts low carbon technologies, such as fuel cell, PV and is running off-grid. The average carbon emission costs of S2 decreases by about $17.09 \%$ and $23.04 \%$ respectively, compared with S3 and S4.

The carbon emission of off-grid mode is always less than grid connected mode, as the electricity from the grid is often generated from coal-fired plants. In this paper, we assume every $\mathrm{kWh}$ electricity from grid can emit $0.537 \mathrm{~kg} \mathrm{CO}_{2}$, based on information from the British Gas website, however this number will decrease as more renewables are integrated. Comparing 

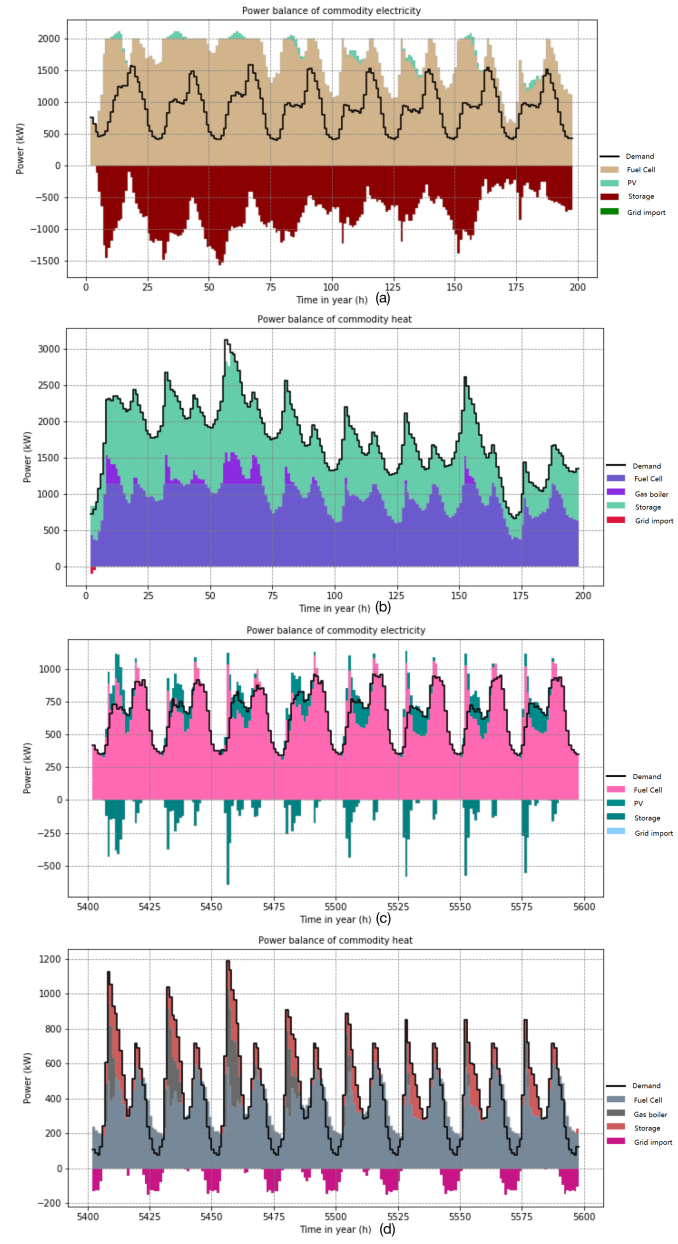

Fig. 7. The hourly energy balance of case 3: (a) Electric power balance in January; (b) Heat power balance in January; (c) Electric power balance in July; (d) Heat power balance in July.

the carbon emissions of uncontrolled charging with smart charging of EVs, smart charging mode is always marginally less than the uncontrolled charging mode. For example, the carbon emissions of case 18 is reduced by $3.89 \%$, compared with case 16.

\section{Reliability assessment}

To analyze the effect of reliability indices on the sizing results, different scenarios by using different reliability index (i.e. LOLP ${ }^{\text {tar }}$ ) are studied and the results are shown in Fig. 9. The system costs are increasing due to the higher level of reliability. Slightly changing the value of LOLP ${ }^{\text {tar }}$ will only influence the operation costs, not the investment cost.

\section{Investment suggestions}

Based on the obtained results of all the scenarios, Case 8 and Case 9 are selected as two of the best options for off-grid and grid-connected modes, considering both the total costs and the carbon emission results. The best configuration of the system is Fuel cell: $1 * 400 \mathrm{~kW}$; CHP:903kW PV: 1050kW; Gas boiler: 776; TS: 500units.
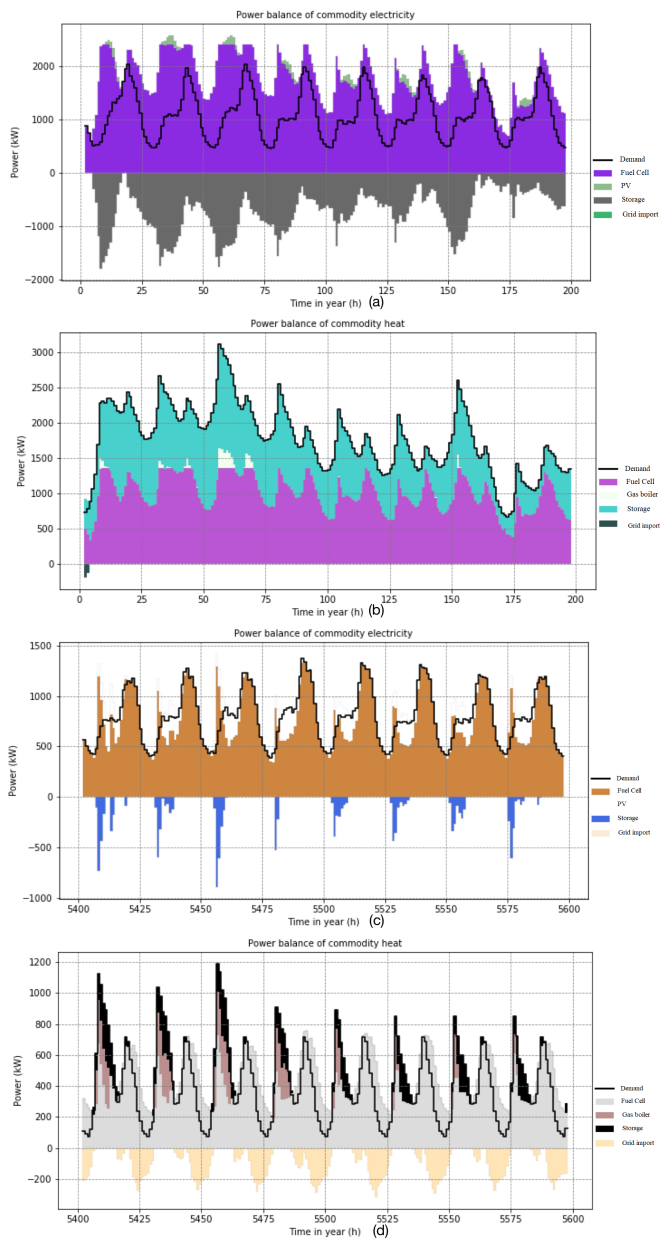

Fig. 8. The hourly energy balance of case 5: (a) Electric power balance in January; (b) Heat power balance in January; (c) Electric power balance in July; (d) Heat power balance in July.

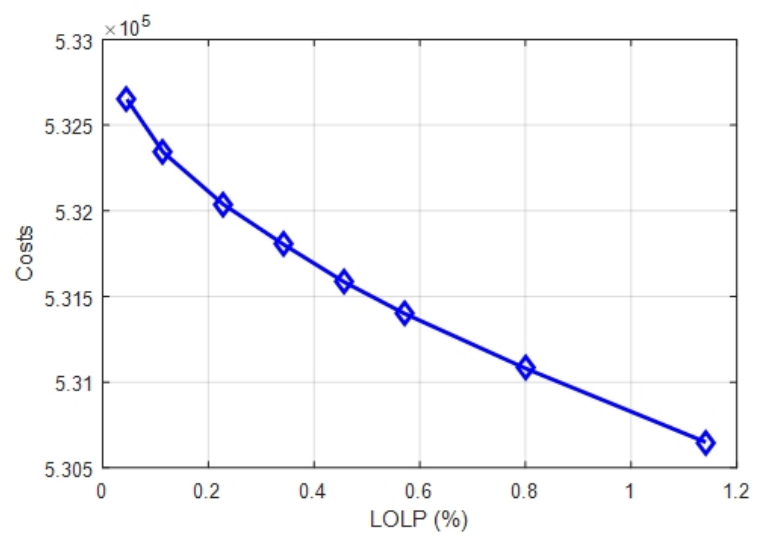

Fig. 9. System costs for different reliability indices. 

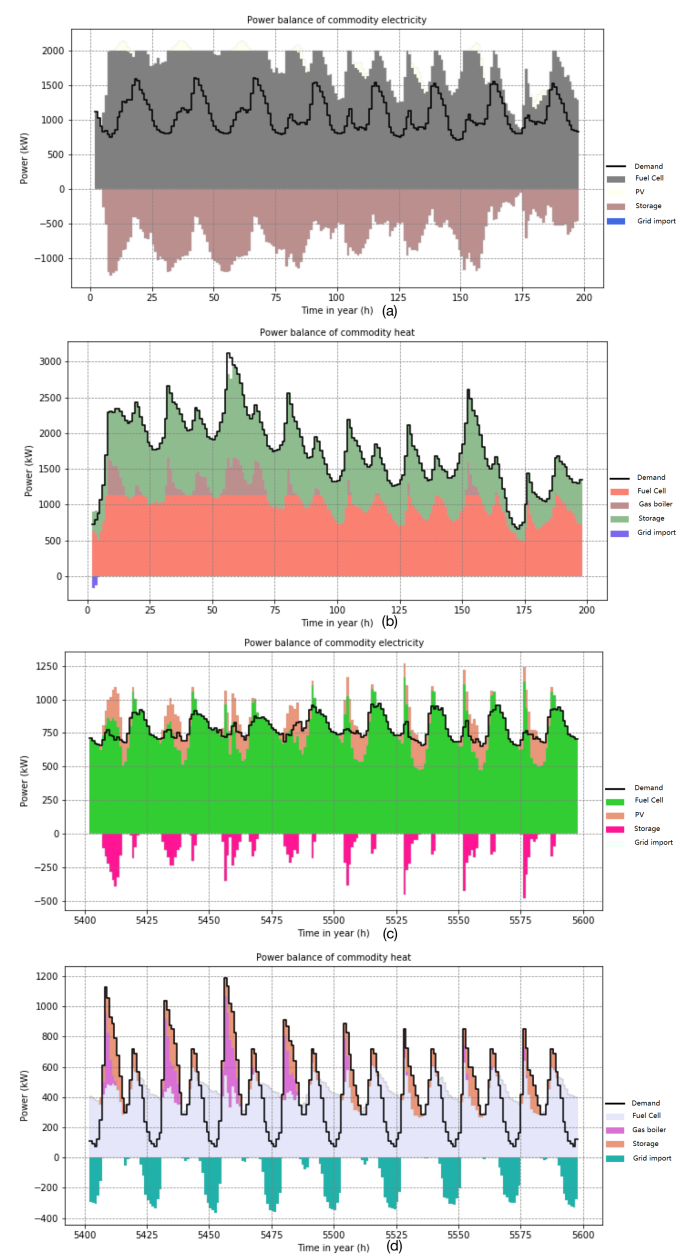

Fig. 10. The hourly energy balance of case 7: (a) Electric power balance in January; (b) Heat power balance in January; (c) Electric power balance in July; (d) Heat power balance in July.

By combining different technologies in cases 8 and 9 , the proposed model can take advantage of both the eco-friendly component such as PV and the energy efficient equipment such as CHP, by utilizing the proposed optimization method.

\section{CONCLUSIONS}

In this paper, an Eco-town based multi-energy system in UK was simulated to find the optimal size and operation strategy of mixed technologies such as fuel cell, CHP, gas boiler and PV to meet the electric and thermal loads. A simple transportation electrification model which considers both the uncontrolled and smart charging of EVs is proposed based on the UK national travel survey data. To illustrate how the proposed method works, several cases which adopt different low carbon technologies are compared. Simulation results of several cases show that by utilizing mixed technologies (e.g. case 9 combining CHP, fuel cell, PV, gas boiler and storage) the proposed model is able to reduce carbon emission dramatically, while maintaining cost effectiveness to some extent. In addition, comparison of the results between smart charging and uncontrolled charging modes show that the costs when considering smart charging will reduce by around $12 \%$.
The proposed model can be utilized to help the planners determine the best combination of different low carbon technologies along with their sizes in order to meet energy demands (both heat and electricity). The proposed model can not only minimize the costs and carbon emission, but also fulfill the system reliability requirements.

\section{REFERENCES}

[1] Z.X. Jing, X.S. Jiang, Q. H. Wu, W. H. Tang and B. Hua, "Modeling and optimal operation of a small-scale integrated energy based district heating and cooling system", Energy, vol. 73, pp. 399-415. 2014.

[2] X. Chen, B. McElroy, and C. Kang, "Integrated Energy Systems for Higher Wind Penetration in China: Formulation, Implementation and Impacts," IEEE Transactions on Power Systems, Early Access.

[3] X. Chen, C. Kang and B. McElroy, "Increasing the Flexibility of Combined Heat and Power for Wind Power Integration in China: Modeling and Implementation," IEEE Transactions on Power Systems, Vol. 30, no. 4, pp. 1848-1857, 2015.

[4] C. Shao, Y. Ding, J. Wang, and Y. Song, 'Modeling and Integration of Flexible Demand in Heat and Electricity Integrated Energy System," IEEE Trans. Sustain. Energy, Vol. 9, no. 1, pp. 361-370, 2018.

[5] Y. Li, Y. Zou, Y. Tan, Y. Cao, X. Liu, M. Shahidehpour, 'Optimal Stochastic Operation of Integrated Low-Carbon Electric Power, Natural Gas and Heat Delivery System," IEEE Trans. Sustain. Energy, Vol. 9, no. 1, pp. 273-283, 2018.

[6] Y. Yan, C. Zhang, K. Li and Z. Wang, 'An integrated design for hybrid combined cooling, heating and power system with compressed air energy storage," Applied Energy, Vol. 210, pp. 1151-1166, 2018.

[7] Z. Liu, Y. Chen, R. Zhuo and H. Jia, 'Energy storage capacity optimization for autonomy microgrid considering CHP and EV scheduling," Applied Energy, Vol. 210, pp. 1113-1125, 2018.

[8] S. Mashayekh, M. Stadler, G. Cardoso and M. Heleno, 'A mixed integer linear programming approach for optimal DER portfolio, sizing and placement in multi-energy microgrids," Applied Energy, Vol. 187, pp. 154-168, 2017.

[9] S. Henbest, 'New energy outlook," Bloomberg, Tech. Rep., 2017.

[10] A. Thavlov, "Dynamic optimization of power consumption," M.S. thesis, Tech. Univ. Denmark, Kongens Lyngby, Denmark, 2008.

[11] J. Siroka, F. Oldewurtel, J. Cigler, and S. Pravara, "Experimental analysis of model predictive control for an energy efficient building heating system," Applied Energy, vol. 88, no. 9, pp. 3079-3087, Sep. 2011.

[12] Y. Ma, F. Borrelli, B. Encey, B. Coffey, S. Bengea and P. Haves, "Model Predictive Control for the Operation of Building Cooling Systems," IEEE Transactions on Control Systems Technology, vol. 20, no. 3, pp. 796-803, May. 2012.

[13] Z. Xu, R. Diao, S. Lu, J. Lian, and Y. Zhang, "Modeling of electric water heaters for demand response: A baseline PDE model," in IEEE Transacitons on Smart Grid, Volume 5, no. 5, 2014, Pages 2203-2210.

[14] UK Department for Transport National Travel Survey 2016.

[15] C. Crozier, D. Apostolopoulou, and M. McCulloch "Numerical Analysis of National Travel Data to Assess the Impact of UK Fleet Electrification". eprint arXiv: 1711.01440.

[16] Justine Sears, David Roberts, and Karen Glitman, "A comparison of electric vehicle Level 1 and Level 2 charging efficiency”. SusTech. 2014

[17] W. Hart, C. D. Laird, J.1 Watson, D. Woodruff, G. Hackebeil, B. Nicholson, and J. Siirola "Optimization Modeling in Python". Second Edition. Vol. 67. Springer, 2017.

[18] IBM ILOG CPLEX Optimization Studio V12.6.3 documentation

[19] Load Profile and Their use in Electricity Settlement. http://data.ukedc.rl.ac.uk/browse/edc/efficiency/residential/Load Profile/LoadProfiles.pdf.

[20] A. Shahmohammadi,M. Moradi-Dalvand, H. Ghasemi, and M. S. Ghazizadeh, "Optimal Design of Multicarrier Energy Systems Considering Reliability Constraints," in IEEE Transacitons on Power Delivery, Volume 30, no. 2, 2015, Pages 878-886.

[21] PVWatts, NREL, http://pvwatts.nrel.gov/pvwatts.php 